\title{
Charcot-Marie-Tooth disease type 2R
}

INSERM

\section{Source}

INSERM. (1999). Orphanet: an online rare disease and orphan drug data base. CharcotMarie-Tooth disease type 2R. ORPHA:397968

Charcot-Marie-T ooth disease type $2 \mathrm{R}$ is a rare subtype of axonal hereditary motor and sensory neuropathy characterized by early-onset axial hypotonia, generalized muscle weakness, absent deep tendon reflexes and decreased muscle mass. Electromyography reveals decreased motor nerve conduction velocities with markedly reduced sensory and motor amplitudes. 